\title{
FreEZING AS FrEedoM? \\ A Regulatory ApProach to Elective Egg FreEzing AND WOMEN'S REPRODUCTIVE AUTONOMY
}

\author{
VANESSA GRUBEN ${ }^{*}$
}

\begin{abstract}
This article reviews concerns relating to the safety and efficacy surrounding the medical practice and social impacts of the increasingly popular practice of elective egg freezing. It argues that current regulation is inadequate to ensure this technology promotes women's autonomy and to ensure women are receiving safe and high quality reproductive health care. It concludes by identifying three priority areas where specific regulation is required: information collection and disclosure, informed consent and fertility education, and assessment and counselling.
\end{abstract}

\section{TABLE OF CONTENTS}

I. INTRODUCTION . . . . . . . . . . . . . . . . . . . . 754

II. Elective EgG Freezing: BeAting the ReProductive Clock . . . . . 755

A. How Does Elective EgG Freezing WORK? . . . . . . . . . . . 755

B. How Much Does EgG Freezing Cost? . . . . . . . . . . . . 756

III. Promoting Elective EgG Freezing: ReProductive Control

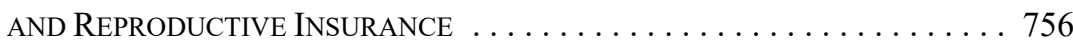

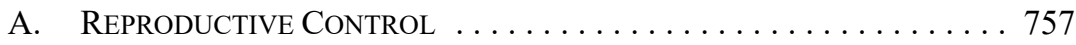

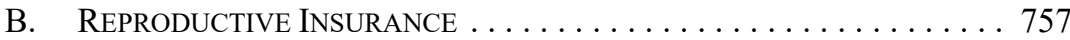

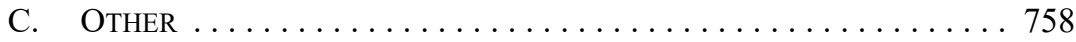

IV. Concerns About Elective EgG Freezing . . . . . . . . . . . . . . . . 759

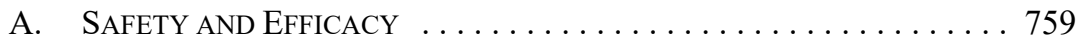

B. The Practice of EgG FreEzING $\ldots \ldots \ldots \ldots \ldots \ldots \ldots \ldots$

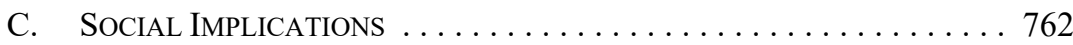

V. Current Regulation of

ASSISTED HUMAN REPRODUCTION IN ONTARIO . . . . . . . . . . . . 763

A. Regulation of REPROdUCtive

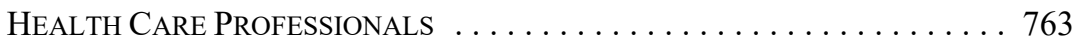

B. Regulation of Fertility Clinics $\ldots \ldots \ldots \ldots \ldots \ldots \ldots 76 \ldots \ldots$

VI. Proposal: Specific Regulation of Elective EgG Freezing . . . . . 766

A. Collection ANd Disclosure of Information $\ldots \ldots \ldots \ldots 767$

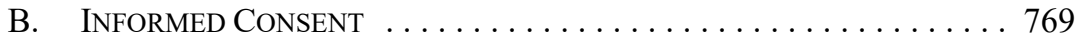

C. Fertility Education, AsSESSMENT, AND CounSELling . . . . . 771

D. Creating an Expert panel on Elective Egg Freezing . . . . . 773

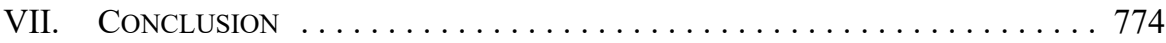

Associate Professor, Faculty of Law, and a member of the Centre for Health Law, Policy and Ethics, at the University of Ottawa. The author would like to thank Alicia Czarnowski for the excellent research assistance and Françoise Moreau-Johnson and Angel Petropanagos for their helpful comments on earlier drafts. 


\section{INTRODUCTION}

Egg freezing is the newest technology to revolutionize women's reproduction. Egg freezing allows a reproductively healthy woman to extract her eggs and store them for use at a later date when she may no longer be fertile. ${ }^{1}$ The market for elective egg freezing has been growing steadily since 2012 when this new freezing technology was declared to no longer be experimental. ${ }^{2}$ Corporate America has also embraced elective egg freezing: Apple, Facebook, and Citigroup all offer to pay for their female employees to freeze and store their eggs. ${ }^{3}$ And most recently, prominent members of the medical community have touted its virtues. Indeed, the New England Journal of Medicine published an article in late 2015 recommending women in their early $30 \mathrm{~s}$ be informed of the option of freezing their eggs for future reproductive use. ${ }^{4}$ The promotion of elective egg freezing has prompted heated debate in the media ${ }^{5}$ and in scholarly articles. ${ }^{6}$ Yet legal scholars have written relatively little about the potential role for law in regulating elective egg freezing. ${ }^{7}$

In this article, I describe the increasingly popular practice of elective egg freezing (also referred to as social egg freezing) and argue that specific legal regulation of elective egg freezing is needed. Elective egg freezing has been heavily promoted to women as a way to "have it all," despite the fact that the evidence in support of its safety and efficacy is quite preliminary. The use of this technology will profoundly impact the way we build our families, as individuals, and as a society. To ensure this technology truly promotes women's autonomy, and to ensure women are receiving safe and high-quality reproductive health care, I argue that greater legal regulation is needed.

In Part II, I provide an overview of how elective egg freezing works and its cost. In Part III, I explore the promotion of egg freezing as a tool of reproductive control and a form of reproductive insurance. In Part IV, I review some of the concerns raised regarding elective egg freezing, including the lack of information on safety and efficacy, gaps in the practice of egg freezing, and the wider social implications of egg freezing. In Part V, I explore the

A woman may choose to freeze her eggs for medical reasons, such as where she is about to undergo chemotherapy treatment that will damage her eggs.

2 American Society for Reproductive Medicine \& Society for Assisted Reproductive Technology, "Mature Oocyte Cryopreservation: A Guideline" (2013) 99:1 Fertility \& Sterility 37 [ASRM Guidelines].

3 Jessica Bennett, "Company-Paid Egg Freezing Will Be the Great Equalizer," Time (15 October 2014), online: <time.com/3509930/company-paid-egg-freezing-will-be-the-great-equalizer/>.

Glenn L Schattman, "Cryopreservation of Oocytes" (2015) 373:18 New Eng J Med 1755 at 1756.

On the in favour side, see e.g. Marcia C Inhorn, "Women, Consider Freezing Your Eggs," CNN (9 April 2013), online: <www.cnn.com/2013/04/09/opinion/inhorn-egg-freezing/>; Sally Satel, "The True Impetus Behind Egg-Freezing," Forbes (21 October 2014), online: <www.forbes.com/sites/sallysatel/ 2014/10/21/the-true-impetus-behind-egg-freezing >. On the against side, see e.g. Viv Groskop, “'Social' Egg-Freezing is a Hideous Fertility Gamble," The Guardian (9 February 2016), online: <www.the guardian.com/commentisfree/2016/feb/09/social-egg-freezing-fertility-infertility-parents-children>; Lynn M Morgan \& Janelle S Taylor, "Egg Freezing: WTF?*" The Feminist Wire (14 April 2013), online: <www.thefeministwire.com/2013/04/op-ed-egg-freezing-wtf/>.

6 In favour, see e.g. Heidi Mertes \& Guido Pennings, "Social Egg Freezing: For Better, Not For Worse" (2011) 23:7 Reproductive BioMedicine Online 824. See also Eli A Rybak \& Harry J Lieman, "Egg Freezing, Procreative Liberty, and ICSI: The Double Standards Confronting Elective Self-Donation of Oocytes" (2009) 92:5 Fertility \& Sterility 1509. Against, see e.g. Gillian M Lockwood, "Social Egg Freezing: The Prospect of Reproductive 'Immortality' or a Dangerous Delusion?" (2011) 23:3 Reproductive BioMedicine Online 334.

7 In the US, see e.g. Seema Mohapatra, "Using Egg Freezing to Extend the Biological Clock: Fertility Insurance or False Hope?" (2014) 8:2 Harvard Law \& Policy Rev 381. In the Canadian context, see Angel Petropanagos et al, "Social Egg Freezing: Risk, Benefits and Other Considerations" (2015) 187:9 CMAJ 666. 
current regulation of assisted human reproduction and conclude that it does not adequately address elective egg freezing. Finally, in Part VI, I recommend three priority areas where specific regulation of elective egg freezing is required: information collection and disclosure, informed consent and fertility education, and assessment and counselling. I also recommend the creation of an expert panel with a mandate to examine the practice of elective egg freezing in its broader social context and make recommendations regarding possible further regulation of elective egg freezing and associated areas such as employee benefit policies.

\section{Elective EgG Freezing: BeAting THE REPROduCTIVE CLOCK}

More and more women are freezing their eggs to combat reproductive aging. Elective egg freezing addresses the reality that as a woman ages, fertility declines precipitously. Fertility begins to decline significantly after 35 years of age. ${ }^{8}$ This is commonly referred to as the fertility cliff. ${ }^{9}$ The fertility cliff exists not because of the age of a woman's uterus but rather the age of her eggs. ${ }^{10}$ If a woman freezes her eggs when she is young, then she may be able to use them at a later age, increasing her chance of pregnancy.

\section{A. How Does Elective Egg Freezing Work?}

Elective egg freezing is a multi-step process. A woman who is interested in freezing her eggs will first undergo a personalized fertility assessment. This involves measuring a woman's antimullerian hormone levels or determining the number of early-stage developing follicles by way of ultrasound. This assessment is intended to assist a woman in deciding whether she should freeze her eggs and provides an indication of the number of eggs that might be retrieved following ovarian stimulation.

The woman then begins the egg retrieval process. First is ovarian stimulation, where a woman injects herself with medication to stimulate her ovaries to produce more than the usual one egg per cycle. Once the ideal number of eggs has been produced, they are retrieved transvaginally by way of a surgical procedure. The eggs are then frozen or vitrified. This new technique of vitrification, or "rapid freezing," involves exposing eggs to higher concentrations of cryoprotectants for a shorter duration, followed by ultra-rapid cooling. ${ }^{11}$

Should a woman decide to use her frozen eggs later in the hopes of creating a baby, the eggs will be thawed and then fertilized with sperm using intra-cytoplasmic sperm injection (ICSI). ${ }^{12}$ Any resulting embryos will be used in a cycle of in vitro fertilization (IVF). Although this "rapid freezing" technique is still relatively new, there is some early data on

Federation CECOS, D Schwartz \& MJ Mayaux, "Female Fecundity as a Function of Age: Results of Artificial Insemination in 2193 Nulliparous Women with Azoospermic Husbands" (1982) 306:7 New Eng J Med 404.

Linda J Heffner, “Advanced Maternal Age: How Old Is Too Old?”(2004) 351:19 New Eng J Med 1927. Daniel Navot et al, "Age-Related Decline in Female Fertility is Not Due to Diminished Capacity of the Uterus to Sustain Embryo Implantation” (1994) 61:1 Fertility \& Sterility 97.

Demián Glujovsky et al, "Vitrification Versus Slow Freezing for Women Undergoing Oocyte Cryopreservation” (2014) 9 Cochrane Database Systematic Reviews CD010047 at 4, 23.

The American Society of Reproductive Medicine has recommended that ICSI (where sperm is injected directly into the egg) be used to fertilize the egg because of the changes that happen in the egg's protective shell because of the freezing process: ASRM Guidelines, supra note 2 at 38 . 
the chance of a live birth using this technique. This data reveals that the success rate is highly dependent on the age of the eggs. A recent meta-analysis demonstrated that the estimated live birth rate associated with six vitrified warmed eggs was 31.3 percent among women at 25 years of age. ${ }^{13}$ This is roughly comparable to the success rates using fresh eggs. ${ }^{14}$ By contrast, the live birth rate for women at 40 years of age was 13.4 percent. ${ }^{15}$ Thus, at first blush, egg freezing appears to be a viable option for women who want to bear children later in life. However, as is discussed later, much about elective egg freezing is still unknown.

\section{B. How Much Does EgG Freezing Cost?}

The cost of egg freezing is staggering. In Canada, a cycle of stimulation and retrieval ranges from $\$ 3,500$ to $\$ 5,850$, plus the cost of the fertility drugs (approximately $\$ 3500$ ). ${ }^{16}$ Egg storage fees are approximately $\$ 250$ per year. The cost of IVF and ICSI when a woman decides to use the eggs ranges from $\$ 3,000$ to $\$ 4,000$. Based on these figures, the total cost for a woman who freezes her eggs when she is 30 and uses them to conceive one child when she is 40 , would be approximately $\$ 36,500 .^{17}$

Like other reproductive technologies, elective egg freezing is highly lucrative for the fertility industry. ${ }^{18}$ Elective egg banking represents a new (and potentially significant) market: young fertile women. And corporations are eagerly participating in this market. Many corporations, such as Facebook and Apple, have benefit plans that pay for their female employees to freeze their eggs. ${ }^{19}$ For women whose companies do not pay and who cannot afford these staggering fees, some companies like EggBanxx offer financial plans to cover the cost of egg freezing and storage. ${ }^{20}$

\section{Promoting Elective Egg Freezing: REPRODUCTIVE CONTROL AND REPRODUCTIVE INSURANCE}

There has been a barrage of positive messages about elective egg freezing. These slogans originate from a variety of sources, including the fertility industry, the media, scholars, and commentators. The promotion of elective egg freezing focuses on two main messages: it offers reproductive control, and it is a form of reproductive insurance. A brief analysis of these messages reveals much about the context in which women make decisions about

Schattman, supra note 4 at 1758 .

ASRM Guidelines, supra note 2 at 39.

Schattman, supra note 4 at 1758.

Several fertility clinics in Canada offer elective egg freezing, including: ASTRA Fertility Group; ReproMed; IVF Canada; McGill IVF; Genesis Fertility Centre; and Ottawa Fertility Centre, among others.

17 This assumes three cycles of stimulation totalling $\$ 27,000$, plus 10 years of storage totally $\$ 2500$ plus two cycles of IVF/ICSI totalling \$7,000, for a grand total of \$36,500. See also Petropanagos et al, supra note 7 at 667 .

18 See Rene Almeling, Sex Cells: The Medical Market for Eggs and Sperm (Berkeley: University of California Press, 2011).

19 Bennett, supra note 3; Siri Srinivas, "Facebook and Apple to Pay for Female Employees to Freeze Their Eggs," The Guardian (15 October 2014), online: <www.theguardian.com/money/us-money-blog/2014/ oct/14/apple-facebook-pay-women-employees-freeze-eggs $>$.

20 See EggBanxx, "Financing Egg Freezing," online: <https://www.eggbanxx.com/financing-eggfreezing > . A similar service is available in Austria: Ovita, "How Much Does it Cost to Have My Oocytes Cryopreserved?" online: <www.ovita.eu/en-us/kosten.aspx>. 
elective egg freezing, the broader social issues underlying the use of this technology, and the potential role for law.

\section{A. Reproductive Control}

Egg freezing has been promoted as a way for women to take control of their fertility because it allows healthy women to postpone childbearing. In this way, egg freezing promotes reproductive autonomy and gender equality because it allows women to delay childbearing until later, as men are arguably able to do. ${ }^{21}$ Rybak takes the position that elective egg freezing has the "potential to 'level the playing field' for women by permitting them time-unlimited control over their reproductive destiny." 22 Women may choose to postpone motherhood for many reasons. It may allow her to complete her education, to achieve financial stability, or to find a suitable partner. ${ }^{23}$ As a result, elective egg freezing has been compared to the advent of contraception. ${ }^{24}$

This message about reproductive control is reflected in the mainstream media. Op-eds in prominent newspapers like The New York Times, The Wall Street Journal, The Guardian, and The Atlantic promote elective egg freezing. ${ }^{25}$ A cover story on Bloomberg Business News declares, "Freeze your Eggs, Free your Career." ${ }^{26}$ In addition, a number of prominent women have endorsed elective egg freezing as an important tool to control fertility. For example, Anne Marie Slaughter, Princeton professor, former Director of Policy Planning for the US State Department, and mother, in her highly publicized article "Why Women Still Can't Have It All" recommended that young women freeze their eggs. ${ }^{27}$ Feminist anthropologist Marcia Inhorn recommended that her female graduate students freeze their eggs. ${ }^{28}$ Sarah Elizabeth Richards who "stashed away several batches of eggs between the ages of 36 and 38," in an op-ed in The New York Times, called on physicians to counsel patients on egg freezing at their annual checkup. ${ }^{29}$

\section{B. REPRODUCTIVE INSURANCE}

Egg freezing has also been promoted as an important risk management tool to protect against future infertility. In other words, egg freezing is a sort of insurance policy or a form

Mertes \& Pennings, supra note 6 at 825 .

Rybak \& Lieman, supra note 6 at 1509.

WJ Dondorp \& GMWR De Wert, "Fertility Preservation for Healthy Women: Ethical Aspects" (2009) 24:8 Human Reproduction 1779; Imogen Goold \& Julian Savulescu, "In Favour of Freezing Eggs for Non-Medical Reasons” (2009) 23:1 Bioethics 47; Rybak \& Lieman, supra note 6 at 1509.

Rybak \& Lieman, ibid.

Sarah Elizabeth Richards, "We Need To Talk About Our Eggs," The New York Times (22 October 2012), online: <www.nytimes.com/2012/10/23/opinion/we-need-to-talk-about-our-eggs.html> [Richards, "We Need to Talk"]. See also Sarah Elizabeth Richards, Motherhood, Rescheduled: The New Frontier of Egg Freezing and the Women Who Tried It (New York: Simon \& Schuster, 2013); Sarah Elizabeth Richards, "Why I Froze My Eggs (And You Should, Too)," The Wall Street Journal (3 May 2013), online: <www.wsj.com/articles/SB10001424127887323628004578458882165244260>; Srinivas, supra note 19; Bennett, supra note 3; Anne-Marie Slaughter, "Why Women Still Can't Have It All," The Atlantic (July/August 2012), online: <www.theatlantic.com/magazine/archive/2012/07/why-womenstill-cant-have-it-all/309020/>.

26 Emma Rosenblum, "Later, Baby: Will Freezing Your Eggs Free Your Career?” Bloomberg (17 April 2014), online: <www.bloomberg.com/news/articles/2014-04-17/new-egg-freezing-technology-easeswomens-career-family-angst>.

Slaughter, supra note 25 .

Inhorn, supra note 5.

Richards, "We Need to Talk," supra note 25. 
of proactive medicine. ${ }^{30}$ It addresses the worry held by some women that by the time they are ready to have a baby, they may have difficulty conceiving a healthy child with her own eggs because they are too old. This has prompted some to refer to elective egg freezing as reproductive "insurance." ${ }^{31}$ Indeed, one marketing firm cleverly calls itself "Eggsurance." The message is clear: a responsible woman will make a responsible choice to freeze her eggs. This is reflected in the following advertisement: "Success doesn't just happen, it's planned for." 33

Organizations representing reproductive health care professionals have, to varying degrees, endorsed elective egg freezing as a form of reproductive insurance. ${ }^{34}$ The first organization to do so was the European Society for Reproduction and Embryology (ESHRE), which in 2012, stated that "[o]ocyte cryopreservation should not just be available for women at risk of premature pathogenic or iatrogenic fertility loss, but also for those who want to protect their reproductive potential against the threat of time." ${ }^{35}$ Most recently, the Canadian Fertility and Andrology Society (CFAS) published a position statement in 2014 on egg freezing, describing it as "an option for women wishing to preserve their fertility in the face of anticipated decline." 36

\section{OTHER}

Additional benefits of elective egg freezing are identified primarily in the scholarly literature. Most frequent is the argument that elective egg freezing is one way to address many of the challenges associated with egg donation by third parties. Elective egg freezing will decrease the demand for third party eggs and as such addresses the reality that there are simply not enough donor eggs available for reproductive use $\mathrm{s}^{37}$ and that demand is increasing. ${ }^{38}$ By decreasing demand for donor eggs, elective egg freezing also indirectly addresses concerns about the potential exploitation of women who donate their eggs. ${ }^{39}$ It has also been argued that freezing eggs rather than embryos will decrease the frequency of

$30 \quad$ Alison Motluk, "Growth of Egg Freezing Blurs 'Experimental' Label” (2011) 476 Nature 382.

31 David Molloy et al, “Oocyte Freezing: Timely Reproductive Insurance?” (2009) 190:5 Medical J Australia 247 at 247 .

"Eggsurance," online: <www.eggsurance.com/>.

Progyny Egg Freezing, "Success Doesn't Just Happen, It's Planned For. Join us in \#SF to learn abt \#eggfreezing: RSVP bit.ly/1F6qQXS" (10 June 2015 at 6:58 am), online: Twitter $<$ https://twitter.com/ eggbanxx/status/608634246014623745>.

34 In 2013, the American Society for Reproductive Medicine (ASRM) declared egg freezing to no longer be experimental. But the ASRM has also been more circumspect, concluding "there are not yet sufficient data to recommend oocyte cryopreservation for the sole purpose of circumventing reproductive aging in healthy women": ASRM Guidelines, supra note 2 at 42.

35 ESHRE Task Force on Ethics and Law, "Oocyte Cryopreservation for Age-Related Fertility Loss" (2012) 27:5 Human Reproduction 1231 at 1236 [ESHRE Guidelines].

36 Canadian Fertility and Andrology Society, "Position Statement on Egg Freezing," (Montreal: CFAS, 21 October 2014), online: $<$ https://www.cfas.ca/images/stories/pdf/Position Statement Egg Freezing 2014-10-21.pdf $>$ [CFAS Position Statement].

37 Mertes \& Pennings, supra note 6 at 825 . Third party donor eggs will continue to be sought by those who are single fathers by choice as well as gay men.

38 Dominic Stoop, Ana Cobo \& Sherman Silber, "Fertility Preservation for Age-Related Fertility Decline" (2014) 384:9950 Lancet 1311 at 1312 (noting that demand for donor eggs doubled between 2005 and 2009).

$39 \quad$ Kylie Baldwin et al, "Reproductive Technology and the Life Course: Current Debates and Research in Social Egg Freezing" (2014) 17:3 Human Fertility 170 at 171 [Baldwin et al, "Reproductive Technology"]. 
disputes over frozen embryos arising after relationship breakdown as well as controversies over the creation and disposal of surplus embryos. ${ }^{40}$

\section{Concerns About Elective Egg Freezing}

Despite these positive messages, a number of important concerns have been raised about elective egg freezing and some of the practices associated with it. I have grouped these concerns together: first, concerns about the lack of information concerning the safety and efficacy of elective egg freezing; second, concerns related to the "medical" practice of egg freezing (for example, informed consent and absence of standardized protocols); and, third, criticisms related to broader social concerns about elective egg freezing such as its use as a tool to resolve structural problems regarding caregiving and the workplace. Although an exhaustive discussion is beyond the scope of this article, these concerns illustrate the need for greater regulation of elective egg freezing.

\section{A. SAFETY AND EFFICACY}

The first concern is that elective egg freezing is relatively new and there is little data about the success rates and little information regarding the potential risks to women's health and the health of resulting children. ${ }^{41}$

The initial evidence to support the safety and efficacy of elective egg freezing is limited in several ways. As described above, early evidence indicates no significant differences in fertilization rates or live birth rates between fresh oocytes and vitrified oocytes. ${ }^{42}$ Yet, this data is quite preliminary. These studies involve eggs from young, fertile women. ${ }^{43}$ They are based on eggs that have been cryopreserved for a short period of time (usually less than six months). ${ }^{44}$ It is therefore not known whether longer vitrification might damage the egg beyond the normal age-related decrease in egg quality. ${ }^{45}$ This gap in information is especially troubling because egg freezing is being marketed to women in their early 30 s (or younger) for potential use much later. In addition, this data is generated from large programs at experienced centres and there is some question about whether these pregnancy outcomes apply to small or newly established centres. ${ }^{46}$ Further, there is no standardized protocol for egg freezing so it is difficult to make cross-clinic comparisons. ${ }^{47}$ Perhaps the greatest limitation is that less than 2,000 births from vitrified eggs are reported in the medical literature. $^{48}$

$40 \quad$ Ibid at 172.

Françoise Baylis, "Left Out in the Cold: Arguments Against Non-Medical Oocyte Cryopreservation" (2015) 37:1 J Obstetrics \& Gynaecology Can 64 at 64

42 Krinos M Trokoudes, Constantinos Pavlides \& Xiao Zhang, "Comparison Outcome of Fresh and Vitrified Donor Oocytes in an Egg-Sharing Donation Program” (2011) 95:6 Fertility \& Sterility 1996. Schattman, supra note 4 at $1757-58$.

Ibid.

Ibid.

Ibid at 1758 .

Cassie T Wang et al, "Optimized Protocol for Cryopreservation of Human Eggs Improves Developmental Competence and Implantation of Resulting Embryos" (2013) 6:15 J Ovarian Research 1 at 15 .

48 Schattman, supra note 4 at 1758. 
With respect to the potential risk to children, the initial data indicates that, at least in the short-term, cryopreservation does not increase the health risks to children. To date, there appears to be no evidence of congenital abnormalities in children born of vitrified eggs. ${ }^{49}$ However, because this technique is new, there are no long-term studies involving the health of children born from vitrified eggs. ${ }^{50}$ As a result, Schattman concludes there is insufficient data to rule out an increased risk of birth defects or potential long-term adverse effects on children. ${ }^{51}$ Indeed, the ASRM has concluded egg freezing should not be "routinely" used until more detailed long-term data on the health of children is available. ${ }^{52}$

With respect to women's health, the physiological risks associated with ovarian stimulation are not well known. Again, the short-term risks associated with ovarian stimulation $^{53}$ and egg retrieval ${ }^{54}$ are well documented. But the long-term risks are not wellunderstood. There are some reports of increased cancer risks for women who undergo ovarian stimulation. ${ }^{55}$ More long-term data is required. Further, there are additional risks of pregnancy at an advanced age for women and children. Depending on health status and age, women are at an increased risk of gestational diabetes, pre-eclampsia, Caesarean delivery, and preterm delivery with low birth weight. ${ }^{56}$ For children, these risks include premature birth and low birth weight as well as a potential increase in the risk of "congenital structural abnormalities" as well as a "small but increased risk of cancer and structural cardiac anomalies." ${ }^{57}$

Further, little is known about the psychological impact of elective egg freezing on women. To date, there are only a few published studies inquiring into the motivations of women who have chosen elective egg freezing ${ }^{58}$ as well as a few studies of women describing their

Ri-Cheng et al, "Obstetric and Perinatal Outcome in 200 Infants Conceived From Vitrified Oocytes" (2008) 16:5 Reproductive BioMedicine Online 608, online: <www.rbmojournal.com/article/S14726483(10)60471-3/pdf $>$; N Noyes, E Porcu \& A Borin, "Over 900 Oocyte Cryopreservation Babies Born With No Apparent Increase in Congenital Anomolies" (2009) 18:6 Reproductive BioMedicine Online 769, online: <www.rbmojournal.com/article/S1472-6483(10)60025-9/pdf $>$.

Schattman, supra note 4 at 1759 .

Ibid at $1758-59$.

ASRM Guidelines, supra note 2 at 42.

The risks of the stimulation drugs include: fatigue, nausea and vomiting, hot flashes, headache, irritability and moodiness, abdominal discomfort, bloating and temporary weight gain, breast tenderness, constipation and gas, and irritation at the injection site: Mayo Clinic Staff, "In Vitro Fertilization (IVF)" Mayo Clinic, online: <www.mayoclinic.org/tests-procedures/in-vitro-fertilization/details/risks/cmc20207080>.

54 The risks of retrieval complications may include bloating, intra-abdominal bleeding, ovarian torsion, infection, injury, and severe pain: Daniel Bodri et al, "Complications Related to Ovarian Stimulation and Oocyte Retrieval in 4052 Oocyte Donor Cycles" (2008) 17:2 Reproductive BioMedicine Online 237 at 239, online: <www.rbmojournal.com/article/S1472-6483(10)60200-3/pdf >. There is also a risk of developing ovarian hyperstimulation syndrome: Doron Shmorgun \& Paul Claman, "The Diagnosis and Management of Ovarian Hyperstimulation Syndrome" (2011) 33:11 J Obstetrics \& Gynaecology Can 1156 at 1159. See also Annick Delvigne, "Epidemiology of OHSS" (2009) 19:1 Reproductive BioMedicine Online 8, online: <www.rbmojournal.com/article/S1472-6483(10)60040-5/ pdf>.

55 I Rizzuto, RF Behrens \& LA Smith, "Risk of Ovarian Cancer in Women Treated with Ovarian Stimulating Drugs for Infertility" (2013) 8 Cochrane Database Systematic Reviews CD008215. See also Helen Pearson, "Health Effects of Egg Donation May Take Decades to Emerge" (2006) 442 Nature 607. Petropanagos et al, supra note 7 at 667.

Ibid.

Kylie Baldwin et al, "Oocyte Cryopreservation for Social Reasons: Demographic Profile and Disposal Intentions of UK Users" (2015) 31:2 Reproductive BioMedicine Online 239, online: <www.rbm online:com>; Baldwin et al, "Reproductive Technology," supra note 39 at 172. 
experience of freezing their eggs. ${ }^{59}$ While a detailed description of their findings is beyond the scope of this article, such studies provide important information about the positive and negative experiences of women and the need for greater regulation in certain areas. Unfortunately, these studies are quite small and were carried out in countries with different regulatory frameworks and as such are of limited usefulness in the Canadian context.

Importantly, the ASRM has acknowledged these gaps in the medical literature. While it deemed elective egg freezing to no longer be experimental, the ASRM wrote: "there are no data to support the safety, efficacy, ethics, emotional risks, and cost-effectiveness of oocyte cryopreservation for this indication [elective cryopreservation to defer childbearing]. ${ }^{\circ 60}$

\section{B. The Practice of Egg Freezing}

There are also concerns arising from the medical practice of elective egg freezing. Some worry that the information women are receiving about elective egg freezing may undermine the informed consent process. ${ }^{61}$ Concerns about informed consent arise from the lack of available information described earlier as well as the heavy promotion and marketing of elective egg freezing from various sources. As discussed, certain members of the fertility industry (who profit handsomely from this practice) market egg freezing as a form of reproductive insurance to women. This is clearly problematic when there is no guarantee of a live baby from a batch of frozen eggs. ${ }^{62}$ Some of the marketing by the fertility industry is deeply troubling. Not only do these advertisements imply that egg freezing is a guarantee for a future baby, they may mislead women about the age at which egg freezing can occur. ${ }^{63}$ Indeed, one author who writes in support of elective egg freezing, noted with concern the practice of "manipulative, dishonest, and unseemly marketing." 64 These marketing tactics are especially concerning as research shows "women often demonstrate a mistaken faith in the ability of ARTs such as IVF to help them overcome declining fertility.",65

Another concern relating to the medical practice of egg freezing is the lack of standardized criteria governing the process. For example, should there be a restriction on recommending elective egg freezing to women above a certain age? The consensus is egg freezing should be undertaken by women between ages 30 and $35 .^{66}$ Yet the average reported age of women

59 Brooke Hodes-Wertz et al, "What Do Reproductive-Age Women Who Undergo Oocyte Cryopreservation Think About the Process as a Means to Preserve Fertility?" (2013) 100:5 Fertility \& Sterility 1343; Victoria Vallejo et al, "Social and Psychological Assessment of Women Undergoing Elective Oocyte Cryopreservation: A 7-Year Analysis" (2013) 3:1 Open J Obstetrics \& Gynecology 1; D Stoop et al, "Does Oocyte Banking for Anticipated Gamete Exhaustion Influence Future Relational and Reproductive Choices? A Follow-Up of Bankers and Non-Bankers" (2015) 30:2 Human Reproduction 338.

ASRM Guidelines, supra note 2 at 42.

Baylis, supra note 41 at 65 .

As Ronald Fineberg says, "[i]nsurance means you are guaranteed to receive a financial payout or service to compensate you for a loss if a bad event occurs.... [E]gg freezing as it exists today does not protect women from infertility nor does it guarantee them a pregnancy in the future": Ronald F Feinberg, "Elective Egg Freezing: 10 Thoughts from an REI," ObGyn.net (16 October 2014), online: <www. obgyn.net/ivf/elective-egg-freezing-10-thoughts-rei>.

Karey Harwood, "Egg Freezing: A Breakthrough for Reproductive Autonomy?" (2009) 23:1 Bioethics 39 at 45 .

64 Rybak \& Lieman, supra note 6 at 1511.

65 Baldwin et al, "Reproductive Technology," supra note 39 at 176 . The authors note that the knowledge of age-related fertility decline is low and that the presentation of the success of ARTs and celebrity older mothers in popular media may contribute to misperceptions women have. Mertes \& Pennings, supra note 6 at 826. 
who freeze their eggs is $38 .^{67}$ Further, when and how should women be informed of egg freezing? Currently, most women learn about elective egg freezing from advertisements, marketing activities like egg freezing parties, and employers ${ }^{68}$ Other approaches might better promote women's reproductive autonomy. Last fall, Dr. Glenn Schattmann, a reproductive health physician, writing in the New England Journal of Medicine recommended that "[ $t$ ]he possibility of elective cryopreservation of oocytes should be discussed with all women who are in their early 30 s, since the number of available and genetically normal eggs continually decreases over time." ${ }^{, 69}$ It is questionable whether this is the right approach, but this recommendation highlights the absence of a standard approach to fertility education, assessment, and counselling.

\section{SOCIAL IMPLICATIONS}

A third category of concerns relates to the broader context of elective egg freezing and in particular the impact of this practice on society rather than simply on the individual. A brief discussion of the range of critiques is raised here for the purpose of determining the appropriate role for law. ${ }^{70}$ Many have argued elective egg freezing does not resolve the larger societal issues regarding the accommodation of caregiving in the workplace. ${ }^{71}$ Instead, egg freezing simply postpones caregiving to a later time in one's career. ${ }^{72}$ A closely related concern is that women may feel pressured to freeze their eggs for the sake of their careers, especially where this is a "benefit" paid for by the employer. ${ }^{73}$ Further, elective egg freezing is only available to women of high socioeconomic status. The cost means egg freezing is only available for women employed in high wage jobs and "does not necessarily change the game for women who do not have a lot of money (and this includes many racialized women, single women, and sexual minority women)." 74 Thus, it is argued that women would be better off with "paid parental and sick leave, affordable child care, comprehensive health insurance, immigrant health care, and adequate wages." 75

Elective egg freezing has also been criticized for the stereotypes it perpetuates about parenthood and family formation. By marketing elective egg freezing as a choice responsible women make, elective egg freezing promotes the stigma of childlessness and reinforces the gendered expectation that women must become mothers. ${ }^{76}$ Furthermore, egg freezing has been criticized for overemphasizing the importance of genetic connections in family building. Egg freezing reifies the genetic connection between parent and child; family building by donor eggs or adoption are considered to be a second-best option. ${ }^{77}$ Thus, Martin

J Nekkebroeck, D Stoop \& P Deuroey, "A Preliminary Profile of Women Opting for Oocyte Cryopreservation for Non-Medical Reasons" (2010) 25:1 Supplement Human Reproduction 115.

See e.g. EggBanxx, "EggBanxx Egg Freezing Parties," online: <https://www.eggbanxx.com/events $>$. Schattman, supra note 4 at 1756.

See generally Alana Cattapan et al, "Breaking the Ice: Young Feminist Scholars of Reproductive Politics Reflect on Egg Freezing" (2014) 7:2 Intl J Feminist Approaches to Bioethics 236.

Harwood, supra note 63 at 45; Goold \& Savulescu, supra note 23 at 52-57.

Baldwin et al, "Reproductive Technology," supra note 39.

Baylis, supra note 41 at 65 .

Cattapan et al, supra note 70 at 241 [footnotes omitted].

Morgan \& Taylor, supra note 5.

Harwood, supra note 63.

L Schuman et al, "Women Pursuing Non-Medical Oocyte [Cryopreservation] Would Consider NonGenetic Methods of Family Building Such as Adoption or Ovum Donation" (2013) 100:3 Supplement Fertility \& Sterility S66. 
concludes, "[w]hat has been preserved is not their fertility, but the genetic connection" with the resulting child. ${ }^{78}$ Egg freezing also promotes a traditional view of the family: women should freeze their eggs in the hopes of finding a suitable partner rather than opting to raise a child as a single parent.

Elective egg freezing has been criticized for medicalizing reproduction. As Martin explains, this is a medical solution for a (future) medical problem: reproductive ageing and "anticipated infertility." This is particularly problematic as it could apply to a significant number of women who are not, in fact, infertile. By adopting a medicalized approach to reproduction, "treating it as a problem becomes an imperative — not a matter of whether, but of how and when." 80

\section{Current Regulation of ASSisted HuMan ReProduction in ONTARio}

The regulation of assisted human reproduction, including elective egg freezing, is quite limited in many provinces. ${ }^{81}$ An exhaustive description of the regulatory framework for assisted human reproduction in each province is beyond the scope of this article. Yet a brief review of Ontario's regulatory framework illustrates that elective egg freezing is subject to a patchwork of voluntary mechanisms, self-regulatory regimes, and, in fact, many aspects are not regulated at all. ${ }^{82}$ As a result of the current regulatory environment, the health and safety of women who freeze their eggs and their resulting children may be put at risk.

\section{A. Regulation of Reproductive health Care Professionals}

Reproductive health care professionals, such as physicians and nurses, are governed by a patchwork of laws and policies in Ontario. First, they are members of self-regulating bodies. ${ }^{83}$ That is, their conduct is governed by fellow members of their profession through a college (for example, physicians are governed by the College of Physicians and Surgeons of Ontario) and by virtue of the Regulated Health Professions Act, $1991 .{ }^{84}$ Ontario, like the majority of other provinces, does not have a standard specific to assisted human

78 Lauren Jade Martin, “Anticipating Infertility: Egg Freezing, Genetic Preservation, and Risk” (2010) $24: 4$ Gender \& Society 526 at 533 [emphasis in original]. See also Catherine Waldby, "The Oocyte Market and Social Egg Freezing: From Scarcity to Singularity” (2015) 8:3 J Cultural Economy 275 at 281. Martin, ibid at 359.

Ibid at 530 .

The regulation of the medical practice of assisted human reproduction varies from province to province: Reference re Assisted Human Reproduction Act, 2010 SCC 61, [2010] 3 SCR 457.

82 For a detailed discussion, see Colleen M Flood \& Bryan Thomas, "Regulatory Failure: The Case of the Private-For-Profit IVF Sector" in Trudo Lemmens et al, eds, Regulating Creation: The Law, Ethics, and Policy of Assisted Human Reproduction (Toronto: University of Toronto Press, 2017) [forthcoming] [Flood \& Thomas, "Regulatory Failure"]. Indeed, Flood characterizes the regulation of AHR in Ontario as a "regulatory failure" (at 359).

83 For a general description, see Tracey Epps, "Regulation of Health Care Professionals" in Jocelyn Downie, Timothy Caulfield \& Colleen M Flood, eds, Canadian Health Law and Policy, 4th ed (Markham: LexisNexis Canada, 2011) 75.

${ }_{84}$ SO 1991, c 18 [RHPA]. The Health Professions Procedural Code, which is schedule 2 to the RHPA, is deemed to be part of each health profession's constituting Act (RHPA, s 4). 
reproduction. ${ }^{85}$ Many scholars have argued professional self-regulation falls short: enforcement requires patients to complain as opposed to providing for systematic review of members, the process does not provide compensation for victims which reduces the incentive to file a complaint, the sanctions in self-regulatory regimes are weak, and sanctions (other than formal discipline measures) are not available to the public. ${ }^{86}$

In addition, CFAS sets certain practice guidelines for reproductive health care professionals. CFAS has issued clinical practice guidelines on matters like the management of ovarian hyperstimulation syndrome, multiple embryo transfer, and most recently, on third party reproduction. ${ }^{87}$ To date, CFAS has issued a position statement on elective egg freezing but has not developed a clinical practice guideline. Clinical practice guidelines are intended to promote consistent and higher quality care based on up-to-date medical evidence ${ }^{88}$ In certain cases, clinical practice guidelines may also be relied upon to determine the standard of care in medical malpractice suits, discussed below. ${ }^{89}$ While they certainly play an important role, clinical practice guidelines have also been the subject of criticism: they depend largely on the accuracy and availability of scientific evidence, and where that evidence is weak, the resulting guideline is less reliable ${ }^{90}$ they may be disregarded by practitioners for a number of reasons $;{ }^{91}$ there may be biases in their development as the authors may be influenced by industry activities or other institutional relationships, ${ }^{92}$ and there is no standard approach to their development such as who should be involved in the development process (for example, non-physician experts like psychologists, ethicists, lawyers, and the public). ${ }^{93}$

Only the College of Physicians and Surgeons of both Alberta and Saskatchewan have done so, and they do not explicitly address elective egg freezing: College of Physicians \& Surgeons of Alberta, In Vitro Fertilization (IVF): Standards \& Guidelines (Alberta: College of Physicians \& Surgeons of Alberta, 2011), online: <cpsa.ca/wp-content/uploads/2015/03/NHSF IVF Standards - December2011.pdf>; College of Physicians and Surgeons of Saskatchewan, "Standards: Asssisted Reproductive Technology," online: <https://www.cps.sk.ca/imis/Documents/Legislation/Policies/STANDARD\%20-\%20Assisted \%20Reproductive\%20Technology.pdf $>$.

86 Epps, supra note 83 at 85-87; Flood \& Thomas, supra note 82; Glenn Regehr \& Kevin Eva, "SelfAssessment, Self-Direction, and the Self-Regulating Professional" (2006) 449:1 Clinical Orthopaedics \& Related Research 34. Indeed, for these reasons and others, physicians in the UK are no longer selfregulating: Mary Dixon-Woods, Karen Yeung \& Charles L Bosk, "Why is UK Medicine No Longer a Self-Regulating Profession? The Role of Scandals Involving 'Bad Apple' Doctors”' (2011) 73:10 Social Science \& Medicine 1452

87 Canadian Fertility \& Andrology Society, Guidelines for Third Party Reproduction, online: $<\mathrm{https} / / / \mathrm{cfas}$.ca/clinical-practice-guidelines/>.

88 Dylan Kozlick, "Clinical Practice Guidelines and the Legal Standard of Care: Warnings, Predictions, and Interdisciplinary Encounters" (2011) 19 Health LJ 125 at 131. Clinical practice guidelines may be used by a court in establishing the standard of care owed to the patient. This is one of four elements that must be established in order to succeed in a negligence claim: Bernard Dickens, "Medical Negligence" in Downie, Caulfield \& Flood, supra note 83 at 117.

89 Kozlick, ibid at 145. See also Chris Taylor, "The Use of Clinical Practice Guidelines in Determining Standard of Care" (2014) 35:2 J Leg Med 273.

$90 \quad$ Taylor, ibid at 276-77.

91 These reasons may include: lack of awareness, lack of familiarity, lack of agreement, lack of selfefficacy, lack of outcome expectancy, inertia of previous practice, and external barriers such as time or practice circumstances: Brent Graham, "Clinical Practice Guidelines: What Are They and How Should They Be Disseminated?" (2014) 30:3 Hand Clinics 361 at 362-63. The shortcomings are well-illustrated with respect to embryo transfer. In Quebec, single embryo transfer was mandated by law and as a result, sharply decreased. By contrast, there has been a gradual decrease in the remaining provinces.

92 Kozlick, supra note 88 at 139-42. See also KD Boudoulas et al, "The Shortcomings of Clinical Practice Guidelines" (2015) 130:3 Cardiology 187 at 193.

93 Taylor, supra note 89 at 274. In the case of CFAS, it appears that physicians draft the guidelines with limited input from other experts like psychologists, ethicists, and lawyers, or from the public: Canadian Fertility \& Andrology Society, “CPG Manual," online: $<$ https://cfas.ca/guidelines/cpg-manual $>$ [CFAS]. 
Medical negligence claims are another legal mechanism that addresses the misconduct of health care professionals. ${ }^{94}$ As mentioned, clinical practice guidelines may be relevant to setting the standard of care in a medical negligence claim..$^{95}$ Although a full discussion of medical negligence claims is beyond the scope of this article, one author has noted that there are "enormous challenges to successfully litigating medical error" ${ }^{96}$ under the current tort system.

\section{B. Regulation OF FERTILITy CliniCS}

The regulation of fertility clinics is also multifaceted and, in some respects, incomplete. Fertility clinics are regulated in four main ways. The provincial regulations that apply to publicly delivered health care services in private clinics do not apply, for the most part, to fertility clinics. To the extent that the Independent Health Facilities Act applies to fertility clinics, it does not apply to privately funded services such as elective egg freezing. ${ }^{97}$

Fertility clinics are subject to the Out-of Hospital Premises Inspection Program (OHPIP), but again this framework appears to be ill-suited to promoting the health of women who are electing to freeze their eggs. ${ }^{98}$ The OHPIP was developed and is enforced by the College of Physicians and Surgeons of Ontario (CPSO) for clinics where procedures using anaesthesia are performed. The OHPIP standards govern the qualifications of health care professionals who work in the clinic, ${ }^{99}$ physical standards, ${ }^{100}$ procedure standards,,${ }^{101}$ infection control, ${ }^{102}$ and quality assurance. ${ }^{103}$ Since physicians administer anaesthesia for certain procedures in fertility clinics, fertility clinics are subject to this self-regulatory regime. ${ }^{104}$ While the OHPIP does set standards in these areas, they have been described as a relatively weak regulatory tool. ${ }^{105}$ Further, these standards do not address concerns specific to egg freezing, such as the lack of safety data collected about egg freezing or potential shortcomings in the informed consent process (or indeed concerns about IVF generally.) ${ }^{106}$ Notably, at the time of writing the CPSO had undertaken a review of the OHPIP standards in fertility services premises. ${ }^{107}$

CFAS, ibid.

Clinical practice guidelines may be used by a court in establishing the standard of care owed to the patient. This is one of four elements that must be established in order to succeed in a negligence claim: Dickens, supra note 88.

Colleen M Flood \& Bryan Thomas, "Canadian Medical Malpractice Law in 2011: Missing the Mark On Patient Safety" (2011) 86:3 Chicago-Kent L Rev 1053 at 1091.

RSO 1990, c I.3. See Flood \& Thomas, "Regulatory Failure," supra note 82 at 451.

The College of Physicians and Surgeons of Ontario, Out-of-Hospital Premises Inspection Program (OHPIP): Program Standards (September 2013), online: <www.cpso.on.ca/CPSO/media/documents/ CPSO $\% 20$ Members/OHPIP/OHPIP-standards.pdf $>$ [OHPIP Standards]. In Ontario, all IVF services occur in private fertility clinics as opposed to in public hospitals, as is the case in other provinces, such as Quebec.

Ibid at 18-23 covers Medical Director Qualifications, Physician Performing Procedures Qualifications, Physician Administering Anesthesia Qualifications, and Nurse Qualifications.

Ibid at 12-19 covers General Physical Standards, Operating Room Physical Standards, Recovery-Area Physical Standards, General Medication Standards, Controlled Substances Standards, and Drugs for Resuscitation.

Ibid at 24-31 covers Pre-Procedure Patient-Care Standards, Intra-Procedure Care for Sedation, Regional Anesthesia or General Anesthesia and Post-procedure Patient Care.

Ibid at 31 covers Infection Control.

Ibid at 33-35 covers Monitoring Quality of Care.

Ibid. Fertility Clinics qualify as Level 2. For a more detailed discussion, see Flood \& Thomas, "Regulatory Failure," supra note 82.

Flood \& Thomas, "Regulatory Failure," ibid. Ibid.

The College of Physcians and Surgeons of Ontario, "Applying the OHPIP Standards in Fertility Services Premises (Consultation Closed)" (Toronto: CPSO, 2017), online: $<$ policyconsult.cpso.on.ca/ ?page id= $9020>$. 
In addition, certain fertility clinics participate in an accreditation program offered through Accreditation Canada. ${ }^{108}$ Accreditation Canada has established three standards: clinical services, laboratory services, and work with third party donors. ${ }^{109}$ Unfortunately, these standards do not address a number of the concerns specific to elective egg freezing. Voluntary accreditation is laudable and provides patients with an assurance that the clinic has met these standards. Yet, there is some concern that, since they are voluntary, a clinic that may be in breach of one of the standards would likely not submit for accreditation.

Finally, many Canadian fertility clinics provide statistical information about IVF (for example, numbers of cycles of IVF/ICSI, number of singleton and multiple births, number of IVF/ICSI cycles using donor eggs) to a voluntary information registry: CARTR-Plus. ${ }^{110}$ A range of information regarding the number of IVF cycles and their outcome (for example, pregnancy, multiple birth rate) is submitted to CARTR-Plus. ${ }^{111}$ While the CARTR-Plus Registry is an important data collection tool, there are concerns that it does not adequately address the information gaps specific to elective egg freezing. While participating clinics do report the number of cycles started for "oocyte/embryo banking for social reasons," there appears to be no detailed information regarding the length of storage or the outcomes of these particular cycles. Further, it is concerning that information collection is voluntary and there are no penalties for failing to disclose or inadequate disclosure.

While many reproductive health care professionals and clinics have taken important steps to establish standards that promote high quality reproductive health care, more is required. The current framework addresses some aspects of elective egg freezing indirectly, while others are not at all addressed. In my view, what is needed to promote women's reproductive autonomy and to protect and promote the health and safety of women who choose to freeze their eggs and their resulting children are regulatory mechanisms that specifically target elective egg freezing.

\section{Proposal: Specific Regulation OF ELECTIVE EgG FrEEZING}

Both direct and indirect regulations specific to elective egg freezing are important tools to ensure that it is a safe and beneficial option for women and children. Many countries have, to varying degrees, developed standards governing elective egg freezing that apply to reproductive health care providers and fertility clinics. Many aspects of elective egg freezing could be the subject of regulation, from how egg freezing is marketed to the requirements

Accreditation Canada, "Review Our Standards," online: $<$ https://accreditation.ca/review-our-standards $>$. Accreditation Canada, "Assisted Reproductive Technology (ART) Standards for Laboratory Services," online: <https://accreditation.ca/assisted-reproductive-technology-art-standards-laboratory-services $>$. The standards are only available for a fee.

Better Outcomes Registry \& Network Ontario, "CARTR Plus," online: < https://www.bornontario.ca/ en/partnership-projects/cartr-plus/>. In 2013, CARTR merged with Better Outcomes Registry \& Network (BORN) Ontario, the Ontario prenatal registry, to improve data collection for IVF, now referred to as CARTR-Plus. BORN operates the CARTR, Plus system under its status as a prescribed health registry under Ontario's Personal Health Information Protection Act, 2004, SO 2004, c 3, Schedule A.

The information collected includes: the number of IVF cycles conducted and their outcomes, the number of IVF cycles carried out with a woman's own oocytes or third party oocytes, success rates of cycles of IVF with and without ICSI, IVF success rates by patient age, the single and multiple birth rate, preterm births based on the type of IVF cycle. 
for storage and destruction of eggs to the conditions under which employers can offer elective egg freezing as an employee benefit. Further, it may be that comprehensive and direct government regulation of assisted human reproduction generally, including elective egg freezing, is warranted. ${ }^{112}$ The purpose of this article is more modest. I recommend strengthening the existing regulatory framework governing health care professionals and clinics in three areas. These include: collection and disclosure of information; informed consent; and fertility education and counselling. In addition, I propose the creation of an expert body to assist with the regulation of these issues as well as to examine the practice of egg freezing in its wider social context. The purpose of these recommendations is not to restrict women's reproductive autonomy or freedom, but rather to promote informed decision-making and to ensure that women who choose to freeze their eggs for future reproductive use have access to high quality and safe reproductive health care. Any implementation of such regulations should therefore operate with that purpose in mind.

\section{A. COLLECTION AND DISCLOSURE OF INFORMATION}

The first area where greater regulation is needed is the collection and disclosure of information regarding elective egg freezing. As described earlier, there is a significant shortage of data about the safety and efficacy of elective egg freezing. ${ }^{113}$ Data regarding egg freezing is absolutely necessary to ensure egg freezing is safe, to ensure women make an informed choice about whether or not to freeze their eggs, to educate the public, and for future policy-making. ${ }^{114}$

As the 2015 CARTR-Plus data illustrates, limited information is collected about elective egg freezing in Canada, specifically the number of cycles carried out for the purpose of electively freezing one's eggs. ${ }^{115}$ As mentioned, the disclosure of information about assisted human reproduction in Canada is voluntary. ${ }^{116}$ By contrast, other jurisdictions mandate the collection of information pertaining to assisted human reproduction, including elective egg freezing. ${ }^{117}$ For example, the Human Fertilisation and Embryology Authority (HFEA), the United Kingdom's regulatory body, oversees a detailed information registry: it mandates the collection of information and data on each cycle of AHR treatment and records the number of eggs frozen for future reproductive use, ${ }^{118}$ the number of children born from cryopreserved

112 For arguments in favour of greater regulation, see Flood \& Thomas, "Regulatory Failure," supra note 82; Erin Nelson, Law, Policy and Reproductive Autonomy (Oxford: Hart, 2013) at 268-71; Vanessa Gruben, "Women as Patients, Not Spare Parts: Examining the Relationship Between the Physician and Women Egg Providers" (2013) 25:2 CJWL 249.

113 As discussed in Part V above, disclosure to the CARTR-Plus Registry is voluntary.

114 Indeed, the ESHRE guidelines on elective egg freezing recommend information collection on elective egg freezing: ESHRE Guidelines, supra note 35 at 1236.

115 Better Outcomes \& Registry Network Ontario, "CARTR Plus: BORN Information System Enhancements"(3 June 2013), online: < https:/www.bornontario.ca/assets/documents/dataentrytraining/ trainingpresentations/BIS $\% 20$ Enhancements $\% 20$ CARTR $\% 20$ Plus $\% 20$ Data $\% 20$ entry $\% 20$ sites $\% 20$ \%20June\%202013.pdf>.

116 Notably, in Alberta and Saskatchewan, the provincial college standards require the collection and disclosure of information to CARTR. See supra note 85.

For a general overview, see Nelson, supra note 112 at 241-54.

UK, Human Fertilisation \& Embryology Authority, "What We Do" (HFEA, 25 July 2013), online: <www.hfea.gov.uk/133.html>; UK, Human Fertilisation \& Embryology Authority, "Our Role as an Improved Information Provider" (HFEA, 26 September 2009), online: <www.hfea.gov.uk/5443.html>. 
eggs, ${ }^{119}$ and information on adverse events. ${ }^{120}$ Similarly, the Victorian Assisted Reproduction Treatment Authority (VARTA), which is responsible for registering assisted reproductive clinics, requires the collection of information regarding elective egg freezing and provides an annual report on the outcomes for treatment of cryopreserved non-donor eggs. ${ }^{121}$

To ensure that this practice is safe and to determine its efficacy, Canadian fertility clinics should be required to collect and disclose certain information about elective egg freezing. A health care professional should be able to advise a woman who wishes to freeze her eggs in her late 20 s for use when she is in her late 30 s or early 40 s, what the chance of a live birth is as well as the potential health risks for her and her child(ren). What information must be collected to satisfy these purposes? First, to determine success rates, clinics should collect de-identified information regarding live birth rates, broken down on the basis of age and the duration of oocyte cryopreservation. Second, data regarding short- and long-term health risks associated with ovarian stimulation must be collected. Finally, both short- and long-term information regarding the health and development of children born from cryopreserved eggs must be collected. Like other forms of health information, this information must be collected and stored in a manner that respects federal and provincial privacy laws. ${ }^{122}$ It appears that the CARTR-Plus registry is well-suited to collecting and storing this information as it has been collecting information regarding assisted human reproduction on a voluntary basis for several years. In addition, their staff has the expertise to address some of the roadblocks to data collection raised by Schattman such as clinical differences in freezing and thawing techniques. ${ }^{123}$ Further, it is well-placed to consult with key stakeholders about how to collect information effectively and in a way that respects the privacy rights and interests of patients.

In addition to the mandatory collection of this data, additional information, which will lead to a deeper understanding of the practice of elective egg freezing, should be sought on a voluntary basis. For example, the collection of psychosocial information about elective egg freezing, such as women's motivations for choosing elective egg freezing, their experience with the process, and decision-making regarding storage would provide important information regarding the social, economic, and political forces that influence a woman's decision to freeze her eggs. As mentioned earlier, few such studies exist, and similar studies

UK, Human Fertilisation \& Embryology Authority, "Freezing and Storing Eggs”(HFEA, 15 June 2015), online: $<$ www.hfea.gov.uk/46.html $>$ [HFEA, "Freezing and Storing Eggs"].

UK, Human Fertilisation \& Embryology Authority, Annual Report and Accounts 2015/16 (London: Her Majesty's Stationery Office, 2016) at 8, online: <www.hfea.gov.uk/docs/56071_HC_380_WEB_ V0.2.pdf $>$.

121 VARTA was created pursuant to the Assisted Reproductive Treatment Act 2008 (Vic), Part 10. See Australia, Victorian Assisted Reproductive Treatment Authority, Annual Report 2015 (Melbourne: VARTA, 2016) at 32, online: <https://www.varta.org.au/sites/varta/files/public/VARTA\%20Annual \%20Report\%202015.pdf> [VARTA, Annual Report]. Notably, VARTA is responsible for registering assisted reproductive clinics, providing public education, community consultation about assisted human reproduction, and monitoring developments, trends and activities relating to the causes and prevention of infertility. Similarly, in Western Australia the Human Reproductive Technology Act 1991 (WA), establishes the Western Australia Reproductive Technology Council (WARTC). The functions of this Council include formulating a Code of Practice to govern the use of artificial fertilization and storage procedures, to advise about the compliance of licenses, to encourage and facilitate research into the causes and prevention of all types of human infertility and on the social and public health implications of reproductive technology. 
that are larger in scale and Canada-specific would serve as a valuable resource for law and policy-makers.

In addition to the collection of this information, it is necessary that registry information in anonymized form be made available to researchers, stakeholders, and the public. Again, we can look to other jurisdictions for models of information disclosure. For example, the HFEA, pursuant to its educative function, has published a highly accessible information sheet on elective egg freezing that includes detailed information including up-to-date success rates and risk information, on its website. ${ }^{124}$ Similarly, the VARTA reports on the outcomes for treatment of cryopreserved non-donor eggs ${ }^{125}$ and publishes a range of information on its website about social egg freezing. ${ }^{126}$ Ensuring that this information is available to the public for both education and research purposes will promote informed decision-making and good policy-making. ${ }^{127}$

\section{B. INFORMED CONSENT}

A second concern regarding elective egg freezing relates to informed consent. As discussed, there are areas of uncertainty regarding the safety and efficacy of egg freezing. ${ }^{128}$ Further, there is some concern that the persistent marketing of elective egg freezing as a form of "reproductive insurance" to women may undermine the informed consent process. ${ }^{129}$ The doctrine of informed consent seeks to promote patient autonomy and is premised on the principle that patients have a right to make "meaningful decisions" about whether to undergo a medical treatment. ${ }^{130}$ In this section, I offer some preliminary ideas on what information is likely required to promote informed decision-making in this context. Given the limited space available, important questions relating to whether a woman can every truly make an informed choice in the absence of long-term health information, and the shortcomings of the current law of informed consent more generally, are not addressed here.

Canadian law requires that a physician obtain valid informed consent before treating a patient. ${ }^{131}$ To be valid, the consent must be given by a competent individual and it must be free and informed. In addition, the Assisted Human Reproduction Act requires an individual

HFEA, "Freezing and Storing Eggs," supra note 119.

VARTA, Annual Report, supra note 121 at 32.

Victorian Assisted Reproductive Treatment Authority, "Social Egg Freezing," online: <https://www. varta.org.au/information-support/fertility-and-infertility/fertility-preservation/social-egg-freezing > [VARTA, "Social Egg Freezing"].

As discussed above, there are examples of such bodies in other jurisdictions, such as HFEA and VARTA. Other domestic examples include: Ontario, Institute for Clinical and Evaluative Sciences, online: $<$ www.ices.on.ca $>$. Canadian Institute for Health Information "is an independent, not-for-profit organization that provides essential information on Canada's health systems and the health of Canadians.... Our stakeholders use our broad range of health databases, measurements and standards, together with our evidence-based reports and analyses, in their decision-making processes. We protect the privacy of Canadians by ensuring the confidentiality and integrity of the health care information [provided]": Canadian Institute for Health Information, “About CIHI," online: $<$ https://www.cihi.ca/en/ about-cihi>.

Schattman, supra note 4 at 1758 .

See discussion in Part IV, above.

Malette $v$ Shulman (1990), 72 OR (2d) 417 at 423-24.

The physician's duty to obtain informed consent is required by the common law and has been codified in certain provinces. For example, in Ontario, physicians are required to obtain informed consent where any treatment is proposed for an individual: Health Care Consent Act, 1996, SO 1996, c 2, Schedule A, s 10 . 
to consent to certain procedures. ${ }^{132}$ For consent to be free and informed, Canadian courts have explained that physicians must disclose "the material risks, including probability and gravity, grave consequences even if they have a low probability, and what the doctor knows or should know the patient deems relevant; special or unusual risks." 133 Further, the courts have held that when a medical procedure is elective, as is the case with elective egg freezing, a high standard of disclosure applies and even minimal risks must be disclosed. ${ }^{134}$ The question with respect to elective egg freezing is what information is needed to satisfy this legal standard?

Based on the jurisprudence described above, it is likely that three categories of information should be disclosed to women considering elective egg freezing. First, women should be provided with known physical and psychological risks associated with ovarian stimulation, egg retrieval, and IVF and ICSI (including bloating and swelling, ovarian torsion, infection, potential internal bleeding, and, most seriously, ovarian hyperstimulation syndrome). Second, women must be informed about the chance of a successful live birth and the possibility of failure. Women should be informed that there is little data on the success rates of live births resulting from cryopreserved eggs. Women must be informed that they will likely need to undergo multiple cycles to harvest sufficient eggs to have a good chance at a future birth and there is absolutely no guarantee these eggs will later result in a live birth. ${ }^{135}$ Women should be told that freezing at an older age (38 and older) may result in too few eggs or eggs of low quality and as a result there is a very low probability of pregnancy. ${ }^{136}$ Further, because there is no standard protocol for egg freezing and warming techniques, success rates will vary between clinics. ${ }^{137}$ And third, women must be advised the long-term health risks to any resulting child are largely unknown. ${ }^{138}$

Importantly, this list of information is based on a traditional, libertarian approach to informed consent. The shortcomings of such an approach and the importance of taking a relational approach to informed consent have been discussed in other areas of women's health. ${ }^{139}$ While an exhaustive discussion is outside the scope of this article, a relational approach to consent requires us to also consider the social context and constraints within which women are choosing to freeze their eggs.

While there are general legal standards governing informed consent, specific guidance regarding the informed consent process will assist health care professionals in ensuring that women receive the information needed to make an informed decision. CFAS is well-placed to provide such information through a clinical practice guideline specific to elective egg freezing. For example, CFAS has made similar recommendations regarding informed consent

SC 2004, c 2, s 8 .

Patricia Peppin, "Informed Consent" in Downie, Caulfield, \& Flood, supra note 83 at 164. White $v$ Turner (1981), 31 OR (2d) 773 at 792-93. See also Skeels Estate v Iwashkiw, 2006 ABQB 335, [2006] 11 WWR 632 at para 156.

Petropanagos et al, supra note 7 at $667-68$.

Schattman, supra note 4 at 1759.

Ibid.

ASRM Guidelines, supra note 2 at 42; ESHRE Guidelines, supra note 35 at 1236; Petropanagos, supra note 7.

139 See e.g. Jocelyn Downie \& Jennifer Llewellyn, "Relational Theory \& Health Law and Policy" (2008) Health LJ 193 at 206-207, referring to the efficacy of cardiac care for women. See also Nelson, supra note 112 at 43-46.
} 
in its clinical practice guideline on third party reproduction. ${ }^{140}$ In this context, a guideline would offer useful guidance to practitioners, ensure a consistent approach, and provide important information for patients and the public. ${ }^{141}$ The guideline could also be used in the future to establish binding standards on health care professionals and clinics.

\section{Fertility Education, Assessment, AND COUNSElling}

High quality fertility education, assessment, and counselling are essential to ensure that women are able to make well-informed decisions about whether or not to freeze their eggs for future reproductive use. Yet there are many unanswered questions in this context. What are the most effective tools to educate the public about elective egg freezing? What are the best practices for fertility assessment and counselling? Should health care professionals raise the possibility of elective egg freezing or should patients raise this as an option? To truly promote women's reproductive autonomy, it is important to integrate fertility education, assessment, and counselling within the broader framework of sexual and reproductive health care in Ontario.

Who should advise women about elective egg freezing and when? Schattman recommends that women in their early thirties be advised about elective egg freezing. ${ }^{142}$ CFAS, in its position statement on elective egg freezing, "recommends education for young women regarding the effects of aging on fertility and natural conception, as part of routine wellwoman care," 143 but provides few details. And what information should be provided? Petropanagos et al. recommend "[f] amily physicians should be prepared to provide women who ask about social egg freezing with accurate and balanced information on safety and likelihood of a successful outcome, along with similar information about other familymaking choices." "144 In my view, information about elective egg freezing should be included in broader education initiatives about infertility, contraception, and family planning generally.

While women are an obvious target audience for education initiatives, I believe it is equally important that elective egg freezing be included in men's reproductive health education. Men may be directly involved in a family building project where cryopreserved eggs are used; a heterosexual couple may use her cryopreserved eggs, or a single or gay man may use cryopreserved eggs donated by a third party. ${ }^{145}$ A man may be in an intimate relationship with a woman who is considering whether to freeze her eggs for a future reproductive project. And men play key roles in corporations and governments, which are responsible for making decisions regarding elective egg freezing, such as whether to offer

CFAS Guidelines, Third Party Reproduction, online: $<$ https://cfas.ca/my-account/?redirect_to=/wpcontent/uploads/2016/03/Third-Party-Procreation.pdf $>$.

CFAS Position Statement, supra note 36 provides broad recommendations, but no specific guidelines on elective egg freezing in Canada.

Schattman, supra note 4 at 1756 .

CFAS Position Statement, supra note 36.

Petropanagos et al, supra note 7 at 666.

A woman may decide to donate her eggs that she had previously frozen for her own personal use if she does not need them or she has completed her reproductive project. 
this as an employee benefit and whether the public should fund assisted human reproduction, including IVF. ${ }^{146}$

A key component of the elective egg freezing process is the fertility assessment and the subsequent counselling. Under what circumstances should a woman undergo a fertility assessment? Should all women be eligible for a publicly funded fertility assessment at a certain age? And who should counsel the patient following the assessment? It could be argued that a fertility specialist, who may benefit financially from a woman's decision to freeze her eggs, has a conflict of interest, and so the family doctor may be seen as better placed to counsel the patient. ${ }^{147}$ What role, if any, should psychological counselling play in fertility education and assessments? ${ }^{148}$

Other jurisdictions offer interesting models. For example, in Denmark, a Fertility Assessment and Counselling clinic (FAC) offers a free clinical assessment and individual counselling to men and women with no known reproductive problem. ${ }^{149}$ The FAC was developed as an analogy to contraceptive clinics and was created to "prevent infertility and hopefully diminish the demand for fertility treatments" 150 in Finland. In addition to fertility status and reproductive lifespan, the FAC offers fertility advice to men and women.

Public education about elective egg freezing is critical and is a key source of objective information about this practice. Greater public education can work to counteract the persistent, and at times misleading, marketing about elective egg freezing. Various jurisdictions have undertaken public education and awareness campaigns regarding assisted human reproduction and elective egg freezing. For example, the HFEA has created a detailed website with information about risks and benefits, success rates, and the costs associated with elective egg freezing in the United Kingdom. ${ }^{151}$ Similarly, VARTA has published information about elective egg freezing on its website, ${ }^{152}$ and developed popular fertility awareness programs that target age-related infertility. ${ }^{153}$ These public education initiatives could also play an important role in counteracting the gendered expectations about motherhood as well as heteronormative assumptions underlying elective egg freezing by educating the public about other forms of family building like single parenting and adoption.

For example, the city of Urayasu, a city outside of Tokyo, has recently decided to launch a pilot program which subsidizes the cost of women to free their eggs for use in future pregnancies: Justin McCurry, "Japan’s \$1m Fertility Gambit to Help Women Become Mothers," The Guardian (15 July 2016), online: $<$ https://www.theguardian.com/world/2016/jul/15/the-right-thing-to-do-japanese-city-to-offer-eggfreezing-on-public-purse >.

Flood \& Thomas, "Regulatory Failure," supra note 82.

The CFAS guidelines on Assisted Human Reproduction Counseling may offer assistance, but are only available to members.

Helene W Hvidman et al, "Individual Fertility Assessment and Pro-Fertility Counselling; Should This Be Offered to Women and Men of Reproductive Age?" (2014) 30:1 Human Reproduction 9.

Ibid at 10.

HFEA, "Freezing and Storing Eggs," supra note 119.

VARTA, "Social Egg Freezing," supra note 126.

VARTA, Annual Report, supra note 121; Your Fertility, "A Woman's Age Affects Her Fertility," online: <yourfertility.org.au/for-women/age>. The program "Your Fertility" has been viewed more than 2.1 million times. 


\section{Creating an Expert Panel on ELECTIVE EgG FreEzing}

Finally, as with other challenging questions related to infertility and assisted reproduction, the creation of an expert panel or other body to examine the practice of egg freezing in its wider social context would provide valuable advice regarding future regulation. We cannot ignore the social, economic, and political forces that impact a woman's choice to freeze her eggs and the reality that not all women have this choice. ${ }^{154}$ To ensure that elective egg freezing protects and promotes women's reproductive autonomy and the health and safety of women and children, a number of additional regulatory tools may be necessary. An expert panel, with interdisciplinary expertise, would be well-equipped to undertake this broad mandate.

The government of Ontario has struck expert panels in the past to provide advice on important issues relating to assisted reproduction. For example, the Expert Panel on Infertility and Adoption (Expert Panel) was asked to provide advice on how to improve Ontario's adoption system and improve access to fertility monitoring and assisted reproduction services. ${ }^{155}$ Similarly, the provincial government struck a panel to assist it in developing a provincial funding program for infertility services, including IVF. ${ }^{156}$

Like the Expert Panel, the proposed panel should be charged with a broad mandate to examine a range of issues (like those described above) relating to elective egg freezing. The proposed panel should undertake a review of the regulatory tools that currently exist with respect to elective egg freezing and consider whether they are effective. In addition to the areas discussed above, the panel should also inquire into other issues such as storage of frozen eggs ${ }^{157}$ and potential limits on the marketing of elective egg freezing. For example, some scholars have argued that "centres that offer elective oocyte cryopreservation should refrain from specifically targeting those women who are most desperate, namely those older than 35." 158 Further, the panel should be tasked with considering how to best address the constraints women are under to realize educational, personal, and professional goals, for example through improved parental leave policies or more accessible child care programs.

Given the wide range of issues the panel could consider, it would benefit from multidisciplinary expertise. A panel composed of a variety of medical specialists (family, fertility specialists, gynecologists, and obstetricians) as well as psychologists, lawyers, ethicists,

Ontario, Expert Panel on Infertility and Adoption, Raising Expectations: Recommendations of the Expert Panel on Infertility and Adoption (Ontario: Ministry of Children and Youth Services, June 2009), online: $<$ www.children.gov.on.ca/htdocs/English/documents/infertility/RaisingExpectationsEnglish.pdf $>$. Recommendation 1.1 provides:

The Government of Ontario should develop a coordinated public education and social awareness campaign on family building to educate Ontarians about fertility, infertility, assisted reproduction and adoption, and about the resources and options for building or expanding their families (ibid at 22 [emphasis in original]).

156

Ontario, Advisory Process for Infertility Services, Key Recommendations Report (Ontario: Minister of Health and Long-Term Care, 23 June 2015), online: <health.gov.on.ca/en/public/programs/ivf/ docs/ivf_report.pdf $>$.

157 For example, whether there should be time limits on the storage of frozen eggs as exists in other jurisdictions like Victoria, Australia. Another pressing issue is the legal approach to the destruction of abandoned eggs.

158

Mertes \& Pennings, supra note 6 at 825 . 
social scientists, and patients would enable the panel to address various medical, psychological, and social aspects of elective egg freezing. In formulating its recommendations, it would also be useful for the proposed panel to consult with the public, industry, and other regulatory authorities, such as the CPSO, about a range of issues relating to elective egg freezing. In addition, this proposed panel should consult the public and others on these important social, legal, and ethical questions. An interdisciplinary approach to examining the conditions that allow women to make meaningful decisions about reproduction and to advise government as to how to design tools to address these conditions is of utmost importance.

\section{CONCLUSION}

There is little doubt that elective egg freezing is on the rise, yet concerns about this new technology abound. Relatively little is known about its safety and efficacy, there are questions about how and when women learn about and decide to freeze their eggs, and the social impact of this technology is far-reaching. To protect and promote informed decisionmaking and high quality, safe care, direct regulation of reproductive health care professionals and clinics offering elective egg freezing is needed. To do so, we should build on the current regulatory approach and improve the collection and disclosure of information, clarify what information should be provided to ensure free and informed consent, and develop a comprehensive approach to fertility education, assessment, and counselling. In addition, we should create an expert panel to consider the social, economic, and political forces that impact a woman's choice to freeze her eggs and offer proposals for future regulatory reform. These recommendations are mere first steps. We, as a society, must be cognizant of the context in which women decide to freeze their eggs and we must create conditions that allow women to make meaningful and autonomous decisions about family building. 